Review Article

Open Access

\title{
Coronaviruses: a review of their properties and diversity
}

\author{
Joseph, A. A., and *Fagbami, A. H. \\ Department of Microbial Pathology, Faculty of Basic Clinical Sciences, \\ University of Medical Sciences, Ondo, Nigeria \\ *Correspondence to: hfagbami@gmail.com
}

\begin{abstract}
:
Human coronaviruses, which hitherto were causative agents of mild respiratory diseases of man, have recently become one of the most important groups of pathogens of humans the world over. In less than two decades, three members of the group, severe acute respiratory syndrome (SARS) coronavirus (CoV), Middle East respiratory syndrome (MERS)-CoV, and SARS-COV-2, have emerged causing disease outbreaks that affected millions and claimed the lives of thousands of people. In 2017, another coronavirus, the swine acute diarrhea syndrome (SADS) coronavirus (SADS-CoV) emerged in animals killing over 24,000 piglets in China. Because of the medical and veterinary importance of coronaviruses, we carried out a review of available literature and summarized the current information on their properties and diversity. Coronaviruses are single-stranded RNA viruses with some unique characteristics such as the possession of a very large nucleic acid, high infidelity of the RNA-dependent polymerase, and high rate of mutation and recombination in the genome. They are susceptible to a number of physical agents and several chemical agents used for disinfection procedures in hospitals and laboratories. They exhibit considerable genetic and host diversity, causing diseases of gastrointestinal and respiratory system in a wide range of vertebrate hosts including humans. The high prevalence of coronaviruses in domestic and wild animals, especially bats and birds, and the propensity for their genomes to undergo mutation and recombination may lead to emergence of new coronaviruses that could pose a serious threat to human and animal health.
\end{abstract}

Keywords: coronaviruses; SARS-CoV; MERS-CoV; SARS-Cov-2; properties; diversity; review

Received May 5, 2020; Revised May 12, 2020; Accepted May 15, 2020

Copyright 2020 AJCEM Open Access. This article is licensed and distributed under the terms of the Creative Commons Attrition 4.0 International License <a rel="license" href="http://creativecommons.org/licenses/by/4.0/", which permits unrestricted use, distribution and reproduction in any medium, provided credit is given to the original author(s) and the source.

\section{Coronavirus: revue de leurs propriétés et de leur diversité}

\author{
Joseph, A. A., et *Fagbami, A. H. \\ Département de pathologie microbienne, Faculté des sciences cliniques fondamentales, \\ Université des sciences médicales, Ondo, Nigéria \\ *Correspondance à: hfagbami@gmail.com
}

\begin{abstract}
Abstrait:
Les coronavirus humains, qui étaient jusqu'à présent des agents responsables de maladies respiratoires bénignes de l'homme, sont récemment devenus l'un des groupes les plus importants d'agents pathogènes humains dans le monde entier. En moins de deux décennies, trois membres du groupe, le coronavirus (CoV) du syndrome respiratoire aigu sévère (SRAS), le syndrome respiratoire du Moyen-Orient (MERS)-CoV et le SRAS-COV-2, sont apparus, provoquant des épidémies qui ont touché des millions et des personnes. a coûté la vie à des milliers de personnes. En 2017, un autre coronavirus, le coronavirus du syndrome de la diarrhée aiguë du porc (SADS) (SADS-CoV) est apparu chez des animaux tuant plus de 24000 porcelets en Chine. En raison de l'importance médicale et vétérinaire des coronavirus, nous avons effectué une revue de la littérature disponible et résumé les informations actuelles sur leurs propriétés et leur diversité. Les coronavirus sont des virus à ARN simple brin avec certaines caractéristiques uniques telles que la possession d'un très grand acide nucléique, une infidélité élevée de la polymérase dépendante de l'ARN, et un taux élevé de mutation et de recombinaison dans le génome. Ils sont sensibles à un certain nombre d'agents physiques et à plusieurs agents chimiques utilisés pour les procédures de désinfection dans les hôpitaux et les laboratoires. Ils présentent une diversité génétique et hôte considérable, provoquant des maladies du système gastro-intestinal et respiratoire dans un large éventail d'hôtes vertébrés, y compris les humains. La forte prévalence des coronavirus
\end{abstract}


chez les animaux domestiques et sauvages, en particulier les chauves-souris et les oiseaux, et la propension de leurs génomes à subir des mutations et des recombinaisons peuvent conduire à l'émergence de nouveaux coronavirus qui pourraient constituer une menace sérieuse pour la santé humaine et animale.

Mots-clés: coronavirus; SARS-CoV; MERS-CoV; SRAS-CoV-2; Propriétés; la diversité; la revue

\section{Introduction:}

Prior to the emergence of the severe acute respiratory syndrome-coronavirus (SARSCoV) in humans in 2002-2003, coronaviruses were not regarded as important infectious agents of humans because they generally caused mild disease in healthy and immunocompetent individuals. Human coronaviruses (HCoV)-229E and OC43 were first identified in the 1960 s as causative agents of mild upper respiratory illness. About four decades later, two other human coronaviruses, HCoV-HUK1 and HCoV-NL63 were isolated from cases of bronchiolitis and pneumonia, respectively $(1,2,3)$. Between 2002 and 2019, three coronaviruses; SARS-CoV, Middle East respiratory syndrome coronavirus (MERS-CoV), SARS-CoV-2, and one animal coronavirus; swine acute diarrhea syndrome (SADS) coronavirus, have emerged with severe consequences $(4,5,6,7)$.

SARS-CoV was first reported from China as the aetiological agent of a respiratory disease that affected 1755 people, out of which 774 died (4), and in 2012 MERS-CoV emerged in Saudi Arabia also causing a disease of the respiratory tract characterized by high morbidity and high mortality. In all, MERS-CoV affected over 8,000 people in 27 countries with 803 deaths (5). In, 2019, a new coronavirus, SARS-CoV-2 emerged in China initiating a pandemic that has so far sickened over three million people with more than two hundred thousand deaths in more than 190 countries (6). Although SARS-CoV disappeared after two years, sporadic cases of MERS continue to occur in some countries, and SARSCOV-2 continues to spread worldwide (8).

New emerging coronaviruses are viruses that are haboured by wild animals, or those that arose as a result of mutation and genetic recombination. Transmission to humans may occur as a result of encroachment on the habitats of wild animals through recreational activities such as hunting, hiking and mountaineering. Furthermore, projects that include deforestation for urban development and agriculture, the use of wildlife species as companion animals, and activities around live wild animal markets may expose humans to zoonotic corona viruses. In recent years, many researchers have been engaged in virus surveillance in wild animals leading to the discovery of many novel coronaviruses. The identification of these new viruses has been facilitated by the development and availability of new diagnostic tests such as the polymerase chain reaction and viral genome sequencing.

The emergence of SARS-CoV-2, the causative agent of the current pandemic, has stimulated the interest and desire of the general public, scientists and healthcare givers to understand the biology of coronaviruses. The purpose of this review is to provide information on the properties of coronaviruses including their diversity, pathogenicity, and susceptibility to physical and chemical agents. Such information will lead to a better understanding of how new coronaviruses emerge, their zoonotic potential, the diseases they cause, and which types of infection control measures should be put in place to prevent their spread.

\section{Methodology:}

This is a review of published articles and textbooks, printed and online, accessed through matched search using Google and Bing search engines to peruse articles indexed in Google Scholar, PubMed, Scopus, Index Medicus and AJOL. The keywords used for the online search included 'coronaviruses', 'properties', 'SARS COV', 'MERS', 'SARS CoV2' singly and combined. The review of relevant materials was done over a period of 8 weeks between February and April 2020. Documents and materials were reviewed and those that met the criteria in quality and relevance to the topic were selected while others were excluded. In total, four (4) print textbooks, seventy-seven (77) original articles and one (1) committee report were utilized for the review.

\section{Classification of coronaviruses}

Coronaviruses belong to the family coronaviridae which is divided into two subfamilies; orthocoronavirinae and torovirinae. Based on phylogenetic analysis and serological properties, the orthocoronavirinae is divided into four genera; genus alphacoronavirus, genus betacoronavirus, genus deltacoronavirus, and genus gammacoronavirus. The first two genera contain only mammalian coronaviruses while all avian coronaviruses are in the last two genera (9). A few animal coronaviruses have been placed along with the avian species in the genus deltacoronavirus. 


\section{Major properties of coronaviruses}

Coronaviruses are spherical in shape with a diameter of 80-160 nm and an envelope that is covered by widely spaced club or petalshaped projections, $20 \mathrm{~nm}$ in diameter (Fig 1).

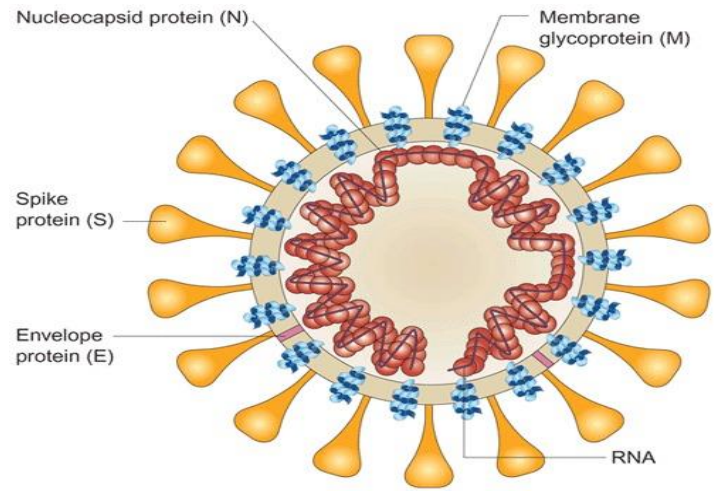

Fig 1: schematic diagram of electron microscopic structure of coronavirus

Source: Peiris, Joseph S. $2005^{81}$

The arrangement of the projections gives the envelope the characteristic crown-like appearance from which the family name 'corona' was derived (10). They have a single-stranded, non-segmented RNA with positive sense, 27-32 $\mathrm{kb}$ in size, and of all RNA genomes, the coronavirus genome is the largest.

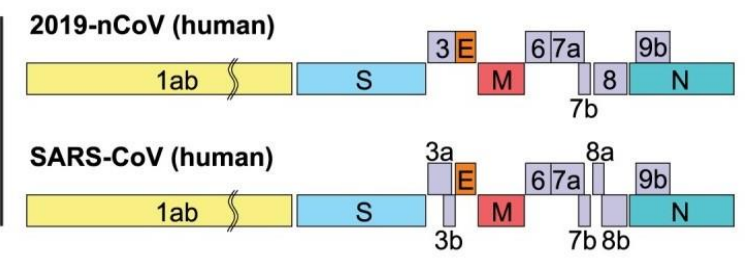

Fig 2: Genomic Organization of SARS-CoV and SARS-CoV-2 (2019-nCoV)

yellow box $=$ open reading frame (orf) $1 \mathrm{ab}$; blue box $=$ spike protein (S); purple boxes = open reading frame (orf) $3,6,7 a, 7 b, 8$ and $9 b$ (accessory proteins); orange box $=$ envelop $(E)$ protein; red box $=$ membrane $(M)$ protein; cyan box $=$ nucleocapsid $(N)$ protein. Source: Chan JF et al. $2020^{82}$.

The RNA is infectious, capped, and polyadenylated (Fig 2), and can serve as mRNA. It encodes four structural proteins, membrane (M) protein, spike protein (S), envelope protein $(E)$, and viral nucleoprotein (N). Some betacoronaviruses have a fifth structural glycoprotein, the haemagglutinin-esterase (HE), on the surface of the virion that is genetically related to a similar protein, the haemagglutininesterase fusion protein of influenza C virus (11). The S protein interacts with specific receptors on the host cell to facilitate attachment, viral entry, and induction of immune response. The genome also encodes nonstructural proteins which include two replicase polyproteins, ORF1a and ORF1b, and between one or more accessory proteins that perform important functions in coronavirus replication and in vivo pathogenesis

\section{Replication of coronavirus}

The replication of coronaviruses is complex and has been previously reviewed by several authors $(12,13)$. To initiate replication, coronavirus attaches to a receptor on the host cell with the aid of the glycoprotein $\mathrm{S}$ on the viral envelope, and $\mathrm{HE}$ in some betacoronaviruses. The receptor for the human coronavirus HCoV$229 \mathrm{E}$ is aminopeptidase N (APN), whereas, it is angiotensin-converting enzyme 2 (ACE-2) for SARS-CoV and SARS-CoV-2, and dipeptyl peptidase 4 (DPP4) for MERS-CoV. Viral entry is facilitated by the fusion of the $S$ protein with the cell membrane, following which the viral genome RNA is uncoated.

The genomic RNA is used as template to translate a polyprotein that is employed to generate an RNA-dependent RNA polymerase, with which a full-length negative strand template is synthesized. Subsequently, the negative strand template is used to generate a nested set of 5-7 subgenomic mRNAs by a discontinuous transcription mechanism (13), and a full-length genomic RNA. These subgenomic mRNA possess common 5' leader and 3 ' terminal sequences. Only the unique sequences at the $5^{\prime}$ end of the mRNAs are translated to form non-structural proteins and structural proteins including $M, E$, $\mathrm{S}$ and $\mathrm{N}$ proteins, and in some viruses, the $\mathrm{HE}$ protein. Newly synthesized genomic RNA molecules and the nucleoprotein assemble in the cytoplasm to form the helical nucleocapsids, which bud through the membranes of the endoplasmic reticulum at the area that contains viral glycoproteins. Mature virions may be transported in vesicles, and released by fusion of the vesicles with plasma membrane $(12,13)$.

\section{Effects of physical and chemical agents on coronaviruses}

Endemic human coronaviruses (HCoV229E, HCoV-OC43, HCoV-NL63 and HCoVHKU1) as well as SARS-CoV and MERS-CoV are susceptible to a number of physical agents including $\mathrm{pH}$, temperature, and relative humidity. They are rapidly inactivated by very acidic and alkaline $\mathrm{pH}$, but are more stable at $\mathrm{pH}$ 6-6.5 $(14,15)$. Exposure of SARS-CoV to temperature of $56^{\circ} \mathrm{C}$ for 30 minutes inactivates it, however, 
in the presence of protein, a higher temperature is required to achieve virus inactivation. Dried virus on smooth surfaces remains infectious for over 5 days at temperatures of $22^{\circ} \mathrm{C}-25^{\circ} \mathrm{C}$ and relative humidity of $40-50 \%$, but virus infectivity was rapidly lost at higher temperatures of up to $38^{\circ} \mathrm{C}$ and relative humidity of $>95 \%$ (15). Chan et al., (15) therefore suggested that the stability of SARS-CoV at temperatures similar to airconditioned room temperatures and low humidity may facilitate cross contamination and virus transmission at home, workplace and public institutions. They further suggested that corona viruses may be inactivated quickly in tropical areas with high ambient temperatures and relative humidity, thereby reducing virus transmission and spread in communities.

Coronaviruses are also susceptible to treatment with several chemical agents and disinfectants as well as antiseptics. As enveloped viruses, they are readily inactivated by ether and chloroform, as well as other chemical agents such as ethanol, propanol, glutaraldehyde, and formaldehyde. According to Kampf (16), human coronaviruses such as SARS-CoV, MERS-CoV and endemic human coronaviruses can persist on inanimate objects like metal, glass, or plastic for up to 9 days, but can be inactivated easily by surface disinfection procedures with $62-71 \%$ ethanol, $0.5 \%$ hydrogen peroxide, or $0.1 \%$ hypochlorite within one minute. In another study, it was found that ethanol and isopropanol as well as WHO recommended handrub formulations efficiently inactivated SARS-CoV and SARS-CoV-2 (17). Sattar et al., (18) assessed the virucidal efficacy of several antiseptics and found that hexamidine, chlorhexidine and cetrimide were ineffective against HCoV 229E, but if alcohol was added, both chlorhexidine and cetrimide acquired virucidal properties.

\section{Growth of coronaviruses in tissue culture}

The identification of SARS CoV, SARSCoV-2, and MERS-CoV, and the need to characterize and develop vaccines against them demand that they be adapted to cell cultures so that adequate quantities of infective virus could be available for further studies. Coronaviruses are difficult to propagate in cell cultures and human coronaviruses have traditionally been grown in human organ and cell cultures (12). HCoV-229E grows readily in primary or secondary human embryonic cultures and human fibroblast cell lines, much better than HCoVOC43. The most sensitive cell line for the isolation of these viruses from clinical specimens seems to be the diploid intestinal cell line, MA177 (19).

Studies on the newer coronaviruses showed that clinical isolates of SARS-CoV replicated efficiently in a variety of cell cultures such as VeroE6 and LLC-MK2 (monkey kidney), HEK-293T (human kidney), RK-13 (rabbit kidney), Huh (human hepatocellular carcinoma), and human peripheral blood mononuclear cells (PBMCs) $(20,21)$. Similarly, MERS-CoV grew in monkey kidney cell cultures and Huh cell line, but did not grow in a variety of other cell lines (22). Recent studies have shown that SARSCoV-2 can be propagated in the same cell cultures that are useful for cultivating SARSCoV, and that the primary human airway epithelial cell culture is the most sensitive for growing the virus (23).

\section{Susceptibility of laboratory animals to coronavirus infection}

Laboratory animal models are often used for experimentation towards vaccine or drug development. Such animal models should be susceptible to infection and produce the type of clinical manifestations observed in humans (24). Efforts were made by researchers to develop animal models for SARS-CoV and MERS-CoV, and similar efforts are currently in progress for SARS-CoV-2. In experimental transmission studies, SARS-CoV produced clinical disease in mice, hamsters, ferrets, and subhuman primates, and except for old mice, none developed severe disease $(24,25)$. Similar studies carried out with MERS-CoV have largely been unsuccessful, but subhuman primates and transgenic mice were susceptible to infection (25). Shi et al., in their own studies showed that although SARS-CoV-2 replicated poorly in dogs, pigs, chicken and ducks, the virus grew well in ferrets and cats (26). Other studies have documented severe disease in hamsters infected with SARS-CoV-2 that is similar to the upper and lower respiratory tract disease in humans, and mild disease and asymptomatic infection in rhesus monkeys and mice, respectively $(27,28)$.

\section{Genetics of coronavirus}

Two phenomena, mutation and recombination, account for genetic diversity among viruses. By definition, mutation is a change in the viral genome which can occur by substitution, insertion, and deletion of bases, as a result of the high error rates and lack of an effective proof-reading mechanism in the viral polymerase (12). Coronaviruses exhibit a high frequency of mutation during each replication 
cycle, occurring along the whole length of the genome, and affecting the $S, M, E$, and the $N$ genes, which may have little or no effect on the virus, or in some cases, cause major changes in viral characteristics. These changes can be demonstrated not only experimentally, but also in natural infections. Zhao et al., (29) experimentally showed that accumulations of mutations in the $S$ gene and the accessory gene $5 a$ accounts for loss of pathogenicity of the infectious bronchitis virus (IBV), a coronavirus of chicken.

The porcine respiratory coronavirus, the causative agent of a mild respiratory disease in pigs evolved naturally as an $S$ gene deletion mutant of the transmissible gastroenteritis virus (TGEV) of pigs. The mutation changed the tissue tropism of the virus for the gastrointestinal tract to the respiratory tract (30). Another coronavirus that emerged naturally as a result of mutation is the feline infectious peritonitis virus (FIPV), a mutant of feline enteritis coronavirus (FECV), which unlike its parent coronavirus, FECV, that causes benign enteritis, is very virulent, causing a severe and fatal disease in cats (31). As coronavirus infects new hosts and spreads from person to person, it mutates; and such mutations can be used to determine the source of the virus and monitor its spread. Ruan et al., (32) studied 14 isolates of SARS-CoV and showed that common mutations are associated with geographical origins of infection. Such mutations are now being used by scientists to monitor the trajectory of the current SARS-CoV2 pandemic as it spreads globally.

Recombination occurs often in coronaviruses and is an important mechanism by which viruses generate genetic diversity $(33,34)$, contributing to the emergence and evolution of different coronavirus genotypes and species. Recombination is the exchange of nucleic acid fragments or segments between two different, but closely related viruses, resulting in the production of certain progeny viruses with genes from both parental viruses. It often leads to increase or decrease in virulence, altered host range, and appearance of new viral antigens. Unlike the other non-segmented RNA viruses which exhibit lower recombination rates, the frequency of recombination in coronaviruses is high, and is probably due to the unique mechanism of replication which involves discontinuous transcription and polymerase jumping $(33,34)$.

The biological significance of recombination was recently demonstrated when Jackwood et al., (35) provided an evidence that recombination can directly lead to the emergence of new coronaviruses. He and his coworkers showed that the turkey coronavirus
(TCoV) emerged from a recombination event that replaced the $S$ gene of IBV with an $S$ gene from unidentified source, accompanied by a change in tissue tropism. The recombinant virus acquired enteropathogenic property causing diarrhea in turkeys, whereas, IBV, one of the parent viruses, was pneumotropic. Similarly, Boniotti et al., (36) described the identification of swine enteric coronavirus (SeCoV) which emerged as result of a recombination between TGE and porcine epidemic diarrhea (PED) viruses, and whose pathogenicity for pigs is much less than that of the parental viruses. Recombination is quite common among coronaviruses of wild animals. Lau et al., (37) showed that each of the three deltacoronaviruses isolated in the UAE; falcon coronavirus HKU 27, houbara bustard coronavirus HKU28, and pigeon coronavirus HKU29, originated from recombination between two avian coronaviruses.

\section{Diversity of coronaviruses}

Coronaviruses infect a diverse range of vertebrate hosts including humans, animals, and birds causing diseases of gastrointestinal and respiratory system or both, and some may affect other organ systems including the central nervous system and the renal system, or cause subclinical infection. Within each host specie, many genetically diverse coronaviruses have been identified, mostly among bats and birds.

\section{Human coronaviruses}

The coronaviruses of medical importance are shown in Table 1 . They include four human coronaviruses; $\mathrm{HCoV}$ [HCoV-229E, HCoV-OC43, HCoV-Hong Kong University (HKU) 1 and HCoV-NL63], SARS-CoV, MERS-CoV, and SARS-COV-2. Human coronavirus 229E and OC43 were first isolated in the 1960 s from adult patients with common colds $(38,39)$, and in 2004, HCoV-NL63, also known as New Haven coronavirus, was identified in an infant with bronchiolitis in the Netherlands (40). The HCoVHKU 1 was discovered in 2005 in an elderly man, a Hong Kong resident, who developed pneumonia following a visit to China (41). In general, all these HCOVs, except HKU1, produced mild respiratory disease in infected patients.

SARS-CoV, the causative agent of an atypical pneumonia characterized by a high morbidity and high mortality, was first described in 2002 in China (4). It has been reported in several Asian countries, Europe, and North America, but most cases have occurred in China, Taiwan, Hong Kong, and Canada. The virus has the properties of other coronaviruses; however, 
its genomic sequence is different from that of the HCoVs, although it enters the host cell through ACE-2, like the HCoV NL63 and SARSCoV-2 (30). In 2012, MERS coronavirus, the causative agent of a severe respiratory illness characterized by fever, shortness of breath, pneumonia, and high mortality, was first identified in Saudi Arabia (5). Seven years later in December 2019, a novel coronavirus, the SARS-CoV-2 was identified in patients with pneumonia in Wuhan, Hubei Province, China. The disease caused by this virus, named CoVID19, has affected over 80,000 people with more than 3,000 deaths in China, and over three million cases and 200,000 deaths worldwide (6), SARS-CoV 2 shares about $70 \%$ to $80 \%$ of its genome with SARS-CoV, but it is most genetically related ( $96 \%$ similarity) to a horse shoe bat coronavirus. It uses the same ACE-2 receptor to enter the host cells like SARS-CoV, but has a longer $S$ protein and a different binding region $(42,43,44)$.

All the seven coronaviruses that have caused disease in humans are believed to have a zoonotic origin, transmitted to man from bats or other animals through intermediate hosts that include domestic and wild animals (44-51) (Table 2). Corman et al., (48) proposed the bat origin of HCoV-229E when they detected a bat coronavirus in Ghanaian Hipposideros caffer ruber bats which shared $92 \%$ nucleotide sequence identity with HCoV-229E. Similarly, Donald son et al., (49) and Tao et al., (50) isolated bat coronaviruses that have a close relationship with HCoV-NL63, also supporting the theory of bat origin of HCoV-NL63. Although the probable intermediate host between the bat NL63-related coronavirus and HCoV-NL63 is not known, Crossley et al., (51) identified the alpaca as the probable intermediate host between the bat HCoV-229E-related virus and HCoV-229E. But unlike HCoV-229E and HCoV-NL63 which have ancestral bat origin, $\mathrm{HCOV}-\mathrm{OC} 43$ is believed to have evolved from ancestral BCoV strains that crossed the interspecies barrier from cattle and established infection in humans $(52,53)$.

Table 1: Coronaviruses affecting humans and their classification

\begin{tabular}{|c|c|c|c|}
\hline Coronavirus & Genus & $\begin{array}{l}\text { Year of } \\
\text { Original } \\
\text { Isolation }\end{array}$ & Disease \\
\hline Human coronavirus $229 \mathrm{E}$ & Alpha & 1960s & Mild respiratory disease \\
\hline Human coronavirus NL63 & Alpha & 2005 & Mild respiratory disease \\
\hline Human coronavirus OC43 & Beta & $1960 s$ & Mild respiratory disease \\
\hline Human coronavirus HKU 1 & Beta & 2004 & Pneumonia \\
\hline Severe acute respiratory syndrome CoV & Beta & 2002 & Severe acute respiratory disease \\
\hline Middle East respiratory syndrome CoV & Beta & 2012 & Severe acute respiratory disease \\
\hline Severe acute respiratory syndrome CoV-2 & Beta & 2019 & Severe acute respiratory disease \\
\hline
\end{tabular}

Table 2: Ancestral and intermediate hosts of coronaviruses pathogenic to humans

\begin{tabular}{|c|c|c|c|}
\hline Host & Coronavirus & $\begin{array}{c}\text { Ancestral/Reservoir } \\
\text { Host }\end{array}$ & $\begin{array}{c}\text { Probable } \\
\text { Intermediate Host }\end{array}$ \\
\hline \multirow[t]{7}{*}{ Humans } & Human coronavirus NL63 & $\begin{array}{c}\text { Bat (Perimyotis subflavus, Triaenops } \\
\text { afer) }\end{array}$ & $?$ \\
\hline & Human coronavirus $229 \mathrm{E}$ & Bat (Hipposideros caffer ruber) & Alpaca \\
\hline & Human coronavirus OC43 & Mouse & Cattle \\
\hline & Human coronavirus HKU 1 & Mouse & $?$ \\
\hline & $\begin{array}{l}\text { Severe acute respiratory } \\
\text { syndrome-CoV }\end{array}$ & Bat (Rhinolophus spp) & $\begin{array}{l}\text { Palm civet cat } \\
\text { Raccoon }\end{array}$ \\
\hline & $\begin{array}{c}\text { Middle East Acute respiratory } \\
\text { syndrome-CoV }\end{array}$ & $\begin{array}{c}\text { Bat (Taphozous perforatus, } \\
\text { Rhinopoma hardwickii and Pipistrellus } \\
\text { kuhlii) }\end{array}$ & Dromedary camel \\
\hline & $\begin{array}{l}\text { Severe Acute respiratory syndrome- } \\
\text { CoV-2 }\end{array}$ & Bat (Horseshoe bat) & $\begin{array}{l}\text { ? Mink } \\
\text { ? Pangolin }\end{array}$ \\
\hline
\end{tabular}


Following the emergence of SARS-CoV in 2002, SARS-related viruses in Rhinolophus horseshoe bats and palm civet cats were discovered by scientists. Based on these discoveries, the scientists concluded that SARS-CoV originated from bats and that palm civet cats were the intermediate hosts from which humans acquired infection $(46,54)$. MERS-CoV also emerged in 2012 and subsequent studies led to the isolation of MERS-related CoVs from several species of bats as well as dromedary camels $(45,54)$. Scientists therefore suggested that the natural hosts of MERS-CoV were bats and the intermediate hosts were camels $(45,46,54)$. Similarly, SARS-CoV-2 emerged following virus transmission between a horseshoe bat and an intermediate host which is probably a mink or pangolin or other yet to be identified animals $(44,47)$.

\section{Coronaviruses of domestic animals and birds}

Coronaviruses of domestic animals and birds are found in the four genera of the subfamily coronavirinae; alphacoronavirus, betacoronavirus, deltacoronavirus and gamma- coronavirus. All mammalian coronaviruses except porcine deltacoronavirus, are found in the genus alphacoronavirus and betacoronavirus, whereas, all avian coronaviruses are in the delta and gammacoronavirus. Animal and avian coronaviruses predominantly cause enteric and pulmonary, as well as hepatic, renal and neurological syndromes (55), affecting swine more than any other domestic animal species. In all, there are fourteen coronaviruses of veterinary importance including seven porcine, two each of feline and avian, and one each of bovine, canine, and equine coronaviruses (Table 3 ).

Porcine coronaviruses include the transmissible gastroenteritis virus (TGEV), porcine haemagglutinating encephalomyelitis (PHE), porcine epidemic diarrhea virus (PEDV), porcine respiratory coronavirus (PRCoV), porcine delta coronavirus (PDCoV), swine acute diarrhea syndrome coronavirus (SADS-CoV), and swine enteric coronavirus (SeCoV). All are primarily enteropathogenic, except the PRCoV which is a respiratory pathogen, and all have only one serotype.

Table 3: Important coronaviruses of domestic animals and birds

\begin{tabular}{|c|c|c|c|}
\hline Coronaviruses & Genus & Host & Disease \\
\hline Transmissible gastroenteritis virus & Alpha & Swine & Gastroenteritis \\
\hline Porcine epidemic diarrhea CoV & Alpha & Swine & Gastroenteritis \\
\hline Porcine respiratory CoV & Alpha & Swine & Respiratory disease \\
\hline Swine acute diarrhea syndrome CoV & Alpha & Swine & Diarrhoea \\
\hline Swine enteric coronavirus & Alpha & Swine & Diarrhoea \\
\hline Feline enteritis coronavirus & Alpha & Cats & Enteritis \\
\hline Feline infective peritonitis virus & Alpha & Cats & $\begin{array}{c}\text { Peritonitis, pneumonia, } \\
\text { meningoencephalitis, wasting syndrome }\end{array}$ \\
\hline Canine coronavirus & Alpha & Dogs & Enteritis \\
\hline Canine respiratory CoV & Alpha & Dogs & Respiratory disease \\
\hline Bovine coronavirus & Beta & Cattle & Diarrhoea \\
\hline Equine coronavirus & Beta & Horse & Colic and diarrhoea \\
\hline $\begin{array}{l}\text { Porcine haemagglutinating } \\
\text { encephalomyelitis virus }\end{array}$ & Beta & Swine & $\begin{array}{l}\text { Vomiting, wasting, and } \\
\text { encephalomyelitis }\end{array}$ \\
\hline Porcine deltacoronavirus & Delta & Swine & Diarrhoea \\
\hline Infectious bronchitis virus & Gamma & Chicken & Tracheobronchitis, nephritis \\
\hline Turkey coronavirus & Gamma & Turkey & Bluecomb, Enteritis \\
\hline
\end{tabular}


Transmissible gastroenteritis virus (TGEV) was identified in 1946 in the United States (56) as the causative agent of a disease of pigs characterized by vomiting, profuse diarrhea, weight loss, and dehydration, and $100 \%$ mortality among newborn pigs. Several years after the identification of TGE, another disease of pigs, the porcine haemagglutinating encephalomyelitis (PHE) was reported in Canada, but its viral aetiological agent was not isolated until 1962 (57). Recent genetic studies have shown PHE virus to be closely related to HCoV-OC43 and $\operatorname{BCoV}(53,58)$. Porcine epidemic diarrhea virus (PEDV), a coronavirus that was first described in England in 1971, is similar to TGEV, causing watery diarrhea and vomiting in piglets which often leads to dehydration and death $(58,59)$. The virus was genetically divided into 2 groups: GI and GII, both of which can be further subdivided into subgroups Ia and Ib, and subgroups IIa and IIb, respectively. Members of the subgroups exhibit marked differences in virulence, and sequence analysis of the nucleocapsid protein gene has shown that PEDV is genetically related to $\mathrm{HCoV}-229 \mathrm{E}$ and TGEV $(60,61)$.

In 2009, PDCoV was first reported in China, but its aetiologic role was not determined until 2014, when it caused diarrhea in pigs in the USA (62). The mechanism of the evolution of the virus is not well understood, but based on the widespread prevalence in song birds and data from genomic studies, it probably originated from an ancestral avian PDCoV (62). The virus utilizes a conserved region of the APN gene to infect cells derived from humans and other species (63). Whether or not it will be able to replicate in human cells and cause disease, is yet to be determined. The detection of PDCoV RNA in fecal samples of wild birds, Chinese ferret badgers and leopard cats, and the susceptibility of other animal species to experimental infection, coupled with the presence of APN receptor in many animal species including humans suggest that PDCoV has a broad host range and may have a zoonotic potential $(62,63,64)$.

Swine acute diarrhea syndrome (SADS) $\mathrm{CoV}$ is the causative agent of a fatal swine acute diarrhea, a disease that primarily affects newborn pigs, characterized by severe watery diarrhea, dehydration and death. The virus is a HKU2-like coronavirus isolated in 2016 in China from horseshoe bats, Rhinolophus spp, (7). Recently, Boniotti et al., (36), also reported the identification of another coronavirus, the swine enteric coronavirus (SeCoV), a TGEV/PEDV recombinant virus, the causative agent of watery diarrhea in piglets. It is noteworthy that this recombinant virus is less virulent than TGEV and PEDV, its parental viruses, producing a much lower mortality rate in piglets (65). Before the appearance of PDCoV and SADS-CoV, the porcine respiratory coronavirus (PRCoV) emerged in Belgium in 1984 as a deletion mutant of TGEV and a causative agent of a mild respiratory disease of piglets (30). The rapid spread of PRCoV to many pig farms in many countries led to widespread immunity to the virus as well as TGEV among pigs, thus reducing the veterinary importance of TGEV worldwide $(65,66)$.

Several coronaviruses cause diseases in companion animals, cats and dogs. Feline coronavirus is a common enteric pathogen of cats existing as two biotypes: feline enteritis coronavirus (FECV) and the feline infectious peritonitis virus (FIPV) $(66,67)$. FECV infection is generally asymptomatic, but in young kittens, mild transient diarrhea occurs, which may sometimes be accompanied by vomiting. FIPV, an FECV mutant, is the aetiological agent of an immune-mediated, progressive, and fatal disease occurring often in cats less than two years of age. It may present as the effusive, also known as the 'wet' form in immunocompromised cats with defective cell mediated immunity, or as the non-effusive, otherwise called the 'dry' form in cats with partial cell mediated immunity. The effusive form is characterized by leakage of protein-rich fluid from the blood vessels into the abdominal cavity producing abdominal distension. Cats with the non-effusive form develop pyogranulomatous or granulomatous lesions in several tissues (66).

Canine coronavirus (CCoV) was first identified in 1971 as a causative agent of mild diarrhea in dogs. The disease often occurs in association with canine parvovirus. It is closely related to TGEV, ferret $\mathrm{CoV}$ and feline CoV. Several strains of the virus now exist as a result of mutations in the viral genome $(66,67)$. There are two serotypes of the virus with different biological properties. Serotype I canine coronaviruses grow poorly in tissue culture and have an ill-defined receptor, whereas, serotype II canine coronaviruses grow well in culture, using the APN receptor $(67,68)$. Another coronavirus of dogs is the canine respiratory coronavirus (CRCoV) which was first identified in 2003 as the causative agent of canine infectious respiratory disease of dogs, also known as 'kernel cough' $(66,69)$. The virus is genetically different from the enteric canine coronavirus and belongs to the genus betacoronavirus, unlike the enteric CCoV which is an alphacoronavirus. It is however, genetically similar to the bovine coronavirus (BCoV) and the HCoV-OC43; and possesses a haemagglutinin-esterase (HE) gene 
which is absent from enteric $\operatorname{CCoV}(69$,$) .$ Clinically, the virus infection often presents as a respiratory disease characterized by respiratory distress, pneumonia, anorexia and sometimes, death (66).

Bovine coronavirus (BCoV) causes diseases of respiratory tract in cattle, and produces gastroenteritis or winter dysentery in lactating cows, and shipping fever pneumonia in feedlot cattle (66). The virus was first described as a cause of diarrhea in calves in the USA in 1973, but has now been documented worldwide. Phylogenetic analysis of $\mathrm{BCoV}$ has shown that it is closely related to $\mathrm{HCoV}-\mathrm{OC} 43$, and coronaviruses identified in dogs with respiratory disease, other ruminants with enteric and/or respiratory disease including water buffalo, sheep, goats, camels, Ilama and alpaca, and wild ruminants such as deer, wild cattle, antelopes, giraffe and wild goats (70). Following biological, antigenic and genetic analyses, it was proposed that these bovine-like CoVs be regarded as host range variants of $\mathrm{BCoV}$ rather than distinct virus species (70).

Equine coronavirus is a betacoronavirus causing a disease of horses characterized by fever, anorexia, colic and occasional diarrhea after an incubation period of 2-4 days (66). The disease usually affects horses over two years of age with a morbidity that ranges from $10 \%$ to $83 \%$, and no mortality in most cases. The virus was first isolated from the faeces of a diarrheic foal in 1999 in the USA (71), and was found to be very closely related phylogenetically to $B C o V$, HCoV-OC43, and PHEV (72). Two avian coronaviruses exist; infectious bronchitis virus (IBV) and turkey coronavirus (TCoV). IBV causes a highly infectious upper respiratory tract disease in commercial poultry. Infected chicken presents with watery eyes, mucus in the nares and trachea, gasping breath, cough and tracheal rales. Among layers, there can be a decrease in egg production and egg quality $(55,66)$. Some strains can cause interstitial nephritis, pneumonia due to secondary bacterial infection, air saculitis, and peritonitis. Morbidity is almost $100 \%$, but mortality is low and variable, but could range from $14 \%$ to $82 \%$ depending on age of the birds, virus strain and whether the birds are coinfected or superinfected by other pathogens (66).

Antigenically distinct serotypes of IBV appear from time to time as a result of mutation and recombination (55). IBV and IB-like coronaviruses have been found in other domestic or captive birds including pigeons, ducks, pheasants, guinea fowls and geese that were reared in the vicinity of chickens $(55,66,74)$. Turkey coronavirus was first identified in the United States in 1973 as the causative agent of bluecomb, a disease of turkeys that was first described in 1951 (73). The virus emerged from a recombination event that replaced the $S$ gene of IBV with an $S$ gene from unidentified source (55).

\section{Coronaviruses of laboratory animals}

Four coronaviruses have been identified in laboratory animals; mouse hepatitis virus (MHV), rat coronavirus (also known as sialodacryoadenitis coronavirus), guinea pig coronavirus (causing diarrhea and enteritis), and rabbit coronaviruses (66). Mouse hepatitis virus has two strains; enterotropic and polytropic strains; the former is very common in mouse colonies. Enterotropic strains of MHV are highly contagious, and often cause severe disease in mouse colonies with mortality rate that may be about $100 \%$ among infant mice. Polytropic strains of MHV are less contagious and general cause inapparent infections, although they may occasionally produce neurological disease.

Rat coronavirus (RCoV), a virus that is closely related to $\mathrm{MHV}$, is the causative agent of epizootics of respiratory disease in laboratory rat colonies. There are two prototype strains of the virus; sialodacryoadenitis virus (SADV) and Parker's rabbit coronavirus (RCoV-P) $(75,76,77)$. Both strains infect the respiratory tract but in addition, SDAV can also infect the eye, salivary glands and lacrimal glands. The disease occurs in rats of all ages, but young rats are the most susceptible, developing lower respiratory tract infection which often leads to interstitial pneumonia. Clinical disease in older rats is characterized by nasal and ocular discharge, cervical swelling, photophobia, keratitis, and dyspnea $(66,77)$. Rabbit coronaviruses have not been properly characterized, but have been associated with enteric disease that is characterized by malabsorption and diarrhea.

\section{Coronaviruses of wild animals}

Many coronaviruses of wild mammals and birds have been identified and are found in all the four genera of the family coronaviridae. However, some of these are presumptive new coronaviruses, yet to be approved by the International Committee on Taxonomy of Viruses (ICTV) (78). Of all species of wildlife, the vast majority of coronaviruses found to date were detected in bats and those approved by the ICTV have been placed in two genera; genus alphacoronavirus and betacoronavirus (Table 4). Bat coronaviruses genetically related to coronaviruses of medical importance include the NL-63-related bat CoV, HCoV-229E-related bat 
Table 4: Bat coronaviruses

\begin{tabular}{|c|c|c|}
\hline Genus & Virus & Human/ Animal virus relative \\
\hline \multirow[t]{11}{*}{ Alphacoronavirus } & Bat coronavirus HKU10 & \\
\hline & Bat coronavirus CDPHE15 & \\
\hline & $\begin{array}{l}\text { Rhinolophus ferrumequinum alpha- } \\
\text { coronavirus HuB-2013 }\end{array}$ & \\
\hline & Myotis ricketti alpha CoV Sax 2011 & \\
\hline & Nyctalus relutinus alphaCoV SC-2013 & \\
\hline & NL-63-related bat coronavirus strain & Human CoV NL 63 \\
\hline & HCoV-229E bat coronavirus & Human CoV 229E \\
\hline & Miniopterus bat coronavirus 1 & \\
\hline & Miniopterus bat coronavirus HKU 8 & \\
\hline & Rhinolophus bat coronavirus HKU 2 & $\begin{array}{l}\text { Swine acute diarrhea syndrome virus } \\
\text { (SADSV) }\end{array}$ \\
\hline & Scotophilus bat coronavirus 512 & $\begin{array}{l}\text { Porcine epidemic diarrhea virus } \\
\text { (PEDV) }\end{array}$ \\
\hline \multirow[t]{4}{*}{ Betacoronavirus } & Pipistrellus bat coronavirus HKU 5 & MERS-CoV \\
\hline & Rousettus bat coronavirus HKU 9 & \\
\hline & SARS-related rhinolophus bat CoV & SARS-CoV \\
\hline & Tylonycteris bat CoV & MERS-CoV \\
\hline
\end{tabular}

CoV, SARS-related CoV, and MERS-like bat CoV. Others (Table 4) are genetically related to causative agents of diseases of domestic animals such as the Rhinolophus bat coronavirus HKU 2 which is similar to the aetiological agent of SADS (7), and the Scotophilus bat coronavirus 512 that was found to be very closely related to the PEDV.

Alphacoronaviruses also cause disease in other wild animals such as ferrets, mink, foxes and wild dogs (Table 5). First isolated in 1993, ferret coronavirus, is the causative agent of catarrhal enteritis of ferrets, as well as a systemic disease that resembles the dry form of feline infective peritonitis $(66,67,79)$. Similar coronaviruses have been found in wild canines including foxes, raccoon dogs, wild dogs and mink $(66,80)$. Betacoronaviruses also exist in wild mammals (Table 5), but unlike the alphacoronaviruses, they do not cause disease in their hosts, except the bovine-like coronaviruses that produce gastrointestinal disease in their definitive hosts that include deer, water bucks, giraffe, antelopes and others $(66,70)$.

Many deltacoronaviruses have also been isolated from wildlife in different geographical regions of the world; those approved by the ICTV belong to seven avian coronavirus species and one porcine coronavirus specie (Table 5). However, other deltacoronaviruses have been identified in wild birds by Hong Kong University (HKU) including sparrow coronavirus HKU 19, falcon coronavirus HKU27, Houbara bustard coronavirus HKU 28, pigeon coronavirus HKU29 and quail coronavirus HKU3O (37). These viruses probably cause subclinical disease in their definitive hosts as only the bulbul coronavirus has been associated with respiratory disease. The gammacoronaviruses of wild animals are infectious bronchitis (IB)-like coronaviruses and Beluga whale coronavirus (Table 5).

IB-like coronaviruses detected in birds include coronaviruses of pheasants, gulls, partridges, quails, and peafowls, however, they differ in the clinical manifestations of infection in their definitive hosts. For example, while pheasants develop serious disease characterized by enteritis with renal involvement, other birds such as parrots and partridges develop asymptomatic infection $(55,81)$. Gammacoronaviruses can be transmitted from wild birds to poultry and from poultry to wild birds, and because of their ability to fly long distances they are capable of disseminating coronaviruses from one continent to another $(55,81)$. 
Table 5: Major coronaviruses of non-bat wild mammals and birds

\begin{tabular}{|c|c|c|c|}
\hline Coronavirus & Genus & Host & Disease \\
\hline Ferret coronavirus & Alpha & Ferret & Enteritis, systemic disease \\
\hline Mink coronavirus 1 & Alpha & Mink & Enteritis \\
\hline Canine-like coronavirus & Alpha & Wild dogs, raccoon dog, foxes & Enteritis \\
\hline Hedgehog coronavirus HKU 31 & Beta & Hedgehog & \\
\hline Murine coronavirus & Beta & Rodent & \\
\hline SARS-related palm civet cat CoV & Beta & Civet cat & \\
\hline SARS-related raccoon dog CoV & Beta & Raccoon dog & \\
\hline Bovine coronavirus-like viruses & Beta & $\begin{array}{l}\text { Deer, giraffe, } \\
\text { antelopes, wild dogs } \\
\text { Asian leopard cat }\end{array}$ & Enteritis \\
\hline Asian leopard cat coronavirus & Beta & & \\
\hline Chinese ferret badger coronavirus & Beta & Chinese ferret badger & \\
\hline Bulbul coronavirus HKU 11 & Delta & Bird & Respiratory disease \\
\hline Coronavirus HKU 15 & Delta & Pig & \\
\hline Munia coronavirus HKU 13 & Delta & Bird & \\
\hline Night heron coronavirus HKU 19 & Delta & Bird & \\
\hline Thrush coronavirus HKU 12 & Delta & Bird & \\
\hline White-eye coronavirus HKU 16 & Delta & Bird & \\
\hline Magpie robin Co HKU 18 & Delta & Bird & \\
\hline Wigeon coronavirus HKU 20 & Delta & Bird & \\
\hline Common moorhen Co HKU 21 & Delta & Bird & \\
\hline Avian coronaviruses & Gamma & $\begin{array}{c}\text { Bird (pheasant, peafowl, partridges } \\
\text { quail and parrots) }\end{array}$ & $\begin{array}{l}\text { Respiratory disease, nephritis in } \\
\text { pheasants, enteritis in quail }\end{array}$ \\
\hline Beluga whale coronavirus SW1 & Gamma & Whale & Respiratory disease \\
\hline
\end{tabular}

\section{Conclusions:}

Coronaviruses have caused three major epidemics in the human population that affected more than three million people with several thousand deaths worldwide, thus making them one the most dangerous groups of human pathogens ever known. As respiratory viruses that remain viable in the environment for several days at temperatures similar to room temperature $\left(22^{\circ} \mathrm{C}-25^{\circ} \mathrm{C}\right)$ and relative humidity of $40-50 \%$, they are readily transmissible from person to person via contaminated humans and inanimate objects such as door handles, elevator buttons, and surfaces. However, most coronaviruses including SARS-CoV, MERS-CoV and SARS-CoV-2 are susceptible to several common disinfectants that can be used to disinfect homes, workplace, laboratories, and hospitals, and prevent virus transmission. Coronaviruses are difficult to propagate in vitro, but progress has been made in growing SARS$\mathrm{CoV}$ and SARS-CoV-2 in tissue culture as well as in laboratory animals. The successful adaptation of SARS-CoV-2 to several cell cultures and the susceptibility of laboratory animals to its experimental infection will promote further in vitro and in vivo studies on the virus that could facilitate vaccine, drug, and diagnostic assay development.

Several coronaviruses are circulating in the human population, and a very large number of them exist in domestic and wild animals. Although many domestic animal coronaviruses exist, none of them has so far posed a threat to human health. In contrast, wild animals harbour 
a variety of coronaviruses, some of which have been associated with important human and animal diseases. Given the presence of a large number of coronaviruses in wild animals, the possibility of coinfection of these animals by more than one coronavirus permitting interaction between their genomes, their propensity to undergo mutation and recombination, and their ability to jump interspecies barrier, it is likely that more new coronaviruses will emerge in future that will pose a major threat to human and domestic animal health. As long as humans continue to interface with wild animals in their natural habitats, zoos, and markets or use them as pets, more zoonotic transmissions of animal coronaviruses are likely to occur which could lead to future epidemics, or even pandemics.

\section{References:}

1. Woo, P. C., Lau, S. K., Chu, C. M., et al. Characterization and genome sequence of a novel coronavirus, coronavirus-HKU1 from pneumonia patients. J Virol. 2005; 79: 884-895

2. Esper, F., Weibel, C., Ferguson, D., Landry, M.L., and Kahn, J. S. Evidence of a novel human coronavirus that is associated with respiratory tract disease in infants and young children. J Infect Dis. 2005; 191:492-498.doi:10.1086/428138

3. Fouchier, R. A., Hartwig, N. G., Bestebroer, T. M., et al. A previously undescribed coronavirus associated with respiratory disease in humans. Proc Natl Acad Sci USA. 2004; 101: 6212

4. Drosten, C., Gunther, S., Preiser, W., et al. Identification of a novel coronavirus in patients with severe acute respiratory syndrome. $N$ Engl J Med. 2003;348(20):1967-1976.

doi:10.1056/NEJMoa030747

5. Zaki, A. M., van Boheemen, S., Bestebroer, T. M. et al. Isolation of a novel coronavirus from a man with pneumonia in Saudi Arabia. N Engl J Med. 2012; 367 (19): 1814-1820

6. Zhu, N., Zhang, D., Wang, W., et al. A novel coronavirus from patients with pneumonia in China, 2019. N Engl J Med. 2020; 382: 727-733. doi: $10.1056 /$ NEJMoa2001017

7. Zhou, P., Fan, H., Lan, T., et al. Fatal swine acute diarrhea syndrome caused by an HKU2-related coronavirus of bat origin. Nature. 2018; 556: 255258

8. Hakawi, A., Rose, E., Biggs, H. M., et al. Middle East respiratory syndrome, Saudi Arabia, 2017-2018. Emerg Infect Dis. 2019; 25 (11): 2149-2151 https://dx.doi.org/10.3201/eid2511.190726

9. De Groot, R. J., Baker, S. C., Baric, R., et al. Family Coronaviridae. In: King A. M. Q., Adams, M. J., Carstens, E. B., Lefkowitz, E. J. (Eds). Virus Taxonomy, 2012, Elsevier, Amsterdam: 806-828

10. McIntosh, K. Coronaviruses: A comparative review. Curr Top Microb Immunol. 1974; 63: 85-129 Bosch, B. J., van der Zee, R., de Haan, C. A., and Rottier, P. J. The coronavirus spike protein is a class 1 virus fusion protein: structural and functional characterization of the fusion core complex. J Virol. 2003; 77: 8801-8811

12. Holmes, K. V., and Lai, M. M. Coronaviridae: The viruses and their replication. In: Fields, B. N., Knipe, D. M., Howley, P. M. et al. (eds). Field's Virology (3rd edn.) Lippincott-Ravens Press, Philadelphia, 1996: 1075-1094.

13. Coronaviridae. In: White, D. O., and Fenner, F. J. (eds). Medical Virology (4th edn,), Academic Press, San Diego, New York, Boston, London, Sydney, Tokyo, Toronto: 451-455.

14. Geller, C., Varbanov, M., and Duval, R. E. Human Coronaviruses: Insights into environmental resistance and its influence on the development of new antiseptics. Viruses. 2012; 4: 3044-3068

15. Chan, K. H., Malik Peiris, J. S., Lam, S. Y., et al. The effects of temperature and relative humidity on the viability of SARS coronavirus. Adv Virol. 2011; 20: 734690-7.

16. Kampf, G., Todt, D., Pfaender, S., and Steinmann, E. Persistence of coronaviruses on inanimate surfaces and their inactivation with biocidal agents. J Hosp Infect. 2020; 104 (3): 246 - 251 https://doi,org/10.1016/j.jhin.2020.01.022

17. Kratzel, A., Todt, D., Vkovski, D., et al. Efficient inactivation of SARS-CoV-2 by the World Health Organization (WHO) recommended handrub formulations and alcohols, 2020. https://doi.org/10.110/2020.03.10.986711

18. Sattar, S. A., Springthorpe, V. S., Karim, Y., and Loro, P. Chemical disinfection of non-porous inanimate surfaces experimentally contaminated with four human pathogenic viruses. Epidemiol Infect. 1989. 198 (102): 493-505

19. Kapikian, A. Z , James, H. D Jr, Kelly, S. J, et al. Isolation from man of 'avian infectious bronchitis virus-like' viruses (coronavirus) similar to $229 \mathrm{E}$ virus with some epidemiological observations. J Infect Dis. 1969; 119: 282-290

20. Gillim-Ross, L., Taylor, J., Scholl, D. R., et al. Discovery of novel human and animal cells infected by SARS-CoV by replication-specific multiplex reverse transcription PCR. J Clin Microbiol. 2004; 42 (7): 3196-3206. doi: 10.1128/JCM42.7.3196-3206.2004

21. Kaye, M., Druce, J., Tran, T., et al. SARS-associated coronavirus replication in cell lines. Emerg Infect Dis. $2006 ; 12$ (1): 128-133

doi: 10.3201 /eid1201.05049

22. de Wilde, A. H., Raj, V. S., Oudshoom, D., et al. MERS-coronavirus replication induces in vitro cytopathology and is strongly inhibited by cyclosporine A or interferon alpha treatment. J Gen Virol. 2013; 94 (pt 8): 1749-1760.

doi: $10.1099 /$ vir.0.052910-0

23. Perlman, S. Another decade, another coronavirus. N Engl J Med. 2020; 382: 760-762.

doi: 10.1056/NEJMe2001126.

24. Sutton, T., and Subbarao, K. Development of animal models against emerging coronaviruses: From SARS to MERS coronavirus. Virology. 2015; 479 (480): 247-258.

https://doi.org/10.1016/j.virol.2015.02.030

25. Roberts, A., Lamirande, E. W., Vogel, L., et al. Animal models and vaccines against SARS-CoV. Virus Res. 2008; 133 (1): 20-32. https://doi.org/10.1016/j.virusres.2007.03,025

26. Shi, J., Wen, Z., Zhong, G., et al. Susceptibility of ferrets, cats, dogs and other domesticated animals to SARS coronavirus-2. Science. 2020. doi:10.1126/science.abb7015

27. Bao, L., Deng, W., Gao, H., et al. Reinfection could not occur in SARS CoV-2 infected rhesus macaques. bioRxiv(preprint)

https://doi.org/10.1101/2020.03.13.990226

28. Cohen, J. Mice, hamsters, ferrets, monkeys. Which lab animals can help defeat the new coronavirus? www.scienceMag.org, 2020

29. Zhao, Y., Cheng, J-L., Liu, X-Y., et al. Safety and efficacy of an attenuated Chinese QX-like infectious bronchitis virus strain as a candidate vaccine. Vet Microbiol. 2015; 180 (1-2): $49-58$ https://doi.org/10.1016/j.vetmic.2015.07.036

30. Pensaert, M., Callebaut, P., and Vergote, J. Isolation of a porcine respiratory non enteric coronavirus 
related to TGE. Vet Q. 1986; 8 (3): 257-261.

31. Sharif, S., Arshad, S. S., Hair-Bejo, M., et al. Descriptive distribution and phylogenetic analysis of feline infectious peritonitis virus isolates of Malaysia. Acta Vet Scand. 2010; 52 (1). https://doi.org/10.1186/1751-0147-52-1

32. Ruan, Y., Wei, C. L., Ee, L. A., et al. Comparative full-length genome sequence analysis of 14 SARS coronavirus isolates and common mutations associated with putative origins of infection. The Lancet. 2003.

https://image.thelancet.com/extras/03art4454web.pdf

33. Baric, R. S., Fu, K., Schaad, M. C., and Stohlman, S. A. Establishing a genetic recombination map for murine coronavirus strains A59 complementation groups. Virology. 1990; 177: 646-656

34. Lai, M. M. Genetic recombination in RNA viruses. Curr Top Microbiol Immunol. 1992; 176: 21-32 Jackwood, M. W., Hall, D., and Handel, A. Molecular evolution and emergence of avian gammacoronaviruses. Infect Genet Evol. 2012; 12: 13051311. doi: 1016/j.meegid.2012.05.003

36. Boniotti, M. B., Papetti, A., Lavazza, A., et al. Porcine epidemic diarrhoeal virus and discovery of a recombinant swine enteric coronavirus, Italy. Emerg Infect Dis. 2016; 22: 83: 87

37. Lau, S. K., Wong, E. Y. M., Tsang, C-C., et al. Discovery and sequence analysis of four deltacoronaviruses from birds in the Middle East suggest interspecies jumping and recombination as a potential mechanism of avian to avian and avian to mammalian transmission. J Virol. 2018; 92 (15). doi: $10.1128 / \mathrm{JV} 100265-18$

38. Tyrell, D. A. J., and Bynoe, M. L. Cultivation of a novel type of common cold virus in organ cultures Br Med J. 1965; 1: 1467-1470

39. Hamre, D., and Procknow, J. J. A new virus isolated from the human respiratory tract. 1966; 121: 190193

40. van der Hoek, L, Pyrc, K., Jebbink, M., et al. Identification of a new coronavirus. Nat Med. 2004; 10: 368-373. https://doi.org/10.1038/nm1024

41. Kahn, J. S., and McIntosh, K. History and recent advances in coronavirus discovery. Paed Infect Dis J. $2005 ; 24$ (11): S223 - S227.

doi:10.1097/01.in.0000188166,17324.60.

42. Perlman, S. Another decade, another coronavirus. N Engl J Med. 2020; 382: 760-762.

doi: $10.1056 /$ NEJMe2001126

43. Cecarrelli, M., Berretta, M., Rullo, E. V., et al. Differences and similarities between severe acute respiratory syndrome (SARS) coronavirus (CoV) and SARS-CoV-2. Would a rose by another name smell as sweet? Eur Rev Med Pharm Sci. 2020; 24: 2781-2783

44. Wu, D., Wu, T., Liu, Q., and Yang, Z. The SARSCoV-2 Outbreak: What we know. Int J Infect Dis. 2020; 92: 44-48. https://doi.org/j.ijid.2020.03.004

45. Haagmans, B. L., Dhahiry, S. H., Reusken, C. B., et al. Middle East Respiratory syndrome coronavirus in dromedary camels: An outbreak investigation. Lancet Infect Dis. 2014; 14 (2): 140-145. https://doi.org/10.1016/S1473-3099(13)70690-X.

46. Song, H. D., Tu, C. C., Zhang, G. W., et al. Crossevolution of SARS-CoV in palm civet and humans. Proc Natl Acad Sci USA.2006. 102: 2430-2435

47. Zhou, P., Yang, X-L., Wang, X-G., et al. Discovery of a novel coronavirus with recent pneumonia outbreak in humans and its potential bat origin. BioRxiv 2020 -biorxiv.org Nature. doi: 10.1038/s41586-020-2012-7

48. Corman, V. M., Baldwin, H. J., Tateno, A. F., et al. Evidence for ancestral association of human coronavirus 229E with bats. J Virol. 2015;89: 1185 1187. doi: $10.1128 /$ JVI.01755-15

49. Donaldson, E. F., Haskew, A. N., Gates, J. E., et al.
Metagenomic analysis of the viromes of three North American bat species: Viral diversity among different bat species that share a common habitat. J Virol. 2010; 84 (24): 13004 - 13018 doi:10.1128/JVI.01255-10

50. Tao, Y., Shi, M., Chommanard, C., et al. Surveillance for bat coronavirus in Kenya identifies relatives of human coronavirus NL63 and 229E and their recombination history. J Virol. 2017; 91 (5): e01953-16. doi: 10.1128/JVI.01953-16

51. Crossley, B. M., Mock, R. E., Callison, S. A., and Hietala, S. K. Identification and characterization of a novel alpaca respiratory coronavirus most closely related to the human coronavirus 229E. Viruses. 2012; 4: 3689-3700.

52. Vijgen, L., Keyaerts, E., Moes, E., et al. Complete genomic sequences of human coronavirus OC43: a molecular clock analysis suggests a relatively recent zoonotic transmission event. J Virol. 2005; 79: 1595-1604

53. Vijgen, L., Keyaerts, E., Maes, P., et al. Evolutionary history of the closely related group 2 coronaviruses: porcine haemagglutinating encephalomyelitis virus, bovine coronavirus and human coronavirus OC43. J Virol. 2006; 80: 7270-7274.

54. Cavanagh, D. Coronaviruses in poultry and other birds. J Avian Pathol. 2005; 34 (6): 439 - 448

55. Doyle, L. P., and Hutchings, L. M. A transmissible gastroenteritis in pigs. J Am Vet Ass. 1946; 108: 257

56. Greig, A. S., Mitchell, D., Corner, A. H., et al. A haemagglutinating virus producing encephalomyelitis in baby pigs. Can J Comp Med Vet Sci. $1962 ; 26(3): 49-56$

57. Dong, B., Lu, H., Zhao, K., et al. Identification and genetic characterization of porcine haemagglutinating encephalomyelitis virus from domestic piglets in China. Arch Virol. 2014; 159: 2329-2337. https://doi.org/10.1007/s00705-014-2070-y

58. Song D, Moon H, Kang B. Porcine epidemic diarrhea: a review of current epidemiology and available vaccines. Clin Exp Vaccine Res. 2015; 4 (2): 166-176. doi: 10.7774/cevr.2015.4.2.166.

59. Lee, C., Porcine epidemic diarrhea virus: An emerging and re-emerging epizootic swine virus. Virol J. 2015; 12: 193.

https://doi.org/10.1186/s12985-015-0421-2

60. Kocherhans, R., Bridgen, A., Ackermann, M., et al. Completion of porcine epidemic diarrhea coronavirus (PEDV) genome sequence. Virus Genes $2001 ; 23: 137-144$ https://doi.org/10.1023/A:1011831902219

61. Woo, P. C. Y., Lau, S. K. P., Lam, C. S. F., et al. Discovery of seven novel mammalian and avian coronaviruses in the genus deltacoronavirus supports bat coronaviruses as the gene source of alphacoronavirus and betacoronavirus and avian coronaviruses as the gene source of gammacoronavirus and deltacororonavirus. J Virol. 2012; 86 (7): 3995-4008 doi: 10.1128/JVI.06540-11

62. Boley, P. A., Alhamo, M. A., Lossie, G., et al. Deltacoronavirus infection and transmission in poultry, United States. Emerg Infect Dis. 2020; 26 (2):255-265.

https://dx.doi.org/10.3201/eid2602.190346

63. Li, W., Hulswit, R. J. G., Kenny, S. P., et al. Broad receptor engagement of an emerging global coronavirus may potentiate its diverse cross species transmissibility. Proc Natl Acad Sci USA. 2018; 115 (22):E5135-E5143 https://doi.org/10.1073/pnas.1802879115

64. Wang, Q., Vlasova, A. N., Kennedy, S. P., and Saif, L. Emerging and re-emerging coronaviruses in pigs. Curr Opin Virol. 2019; 34: 39-49 https://doi.org/10.1016/j.coviro.2018.12.001

65. Coronaviridae: In Fenner's Veterinary Virology, 5th 
ed. 2017: 435-461

66. Le Poder, S. Feline and canine coronaviruses: Common genetic and pathobiological features Adv Virol. 2011; 2011: 609465. doi: 10.1155/2011/609465

67. Decaro, N., and Buonavoglia, C. An update on canine coronavirus: viral evolution and pathobiology. Vet Microbiol. 2008; 132 (3-4): 221234

68. Enles, K., Shiu, K-B., and Brownlie, J. Isolation and sequence analysis of canine respiratory coronavirus. Virus Res. 2007; 124: 78-87

69. Amer, H. M. Bovine-like coronaviruses in domestic and wild ruminants. Anim Hith Res Rev. 2018; 19 (2): 113-124

70. Guy, J. S., Brestin, J. J., Breuhaus, B., et al. Characterization of a coronavirus isolated from a diarrheic foal. J Clin Microbiol. 2000; 38 (12): 45234526

71. Zhang, J., Guy, J. S., Snijder, E. J., et al. Genomic characterization of equine coronavirus. Virology. 2007; 369: 92-104

72. Ritchie, A. E., Desmukh, D. R., Larsen, C. T., and Pomeroy, B. S. Electron microscopy of coronaviruslike particles characteristic of turkey bluecomb disease. Avian Dis. 1973; 17: 546-558

73. Canavagh, D., Madwditt, K., Welchman, D., et al Coronaviruses from pheasants (Phasianus colchicus) are genetically related coronaviruses of domestic fowl (infectious bronchitis virus) and turkeys. Avian Pathol. 2002; 31: 81-93.

doi: $10.1080 / 03079450120106651$

74. Bhatt, P. N., Percy, D. H., and Jonas, A. M. Characterization of the virus of sialodacryoadenitis of rats: a member of the Coronavirus group. J Infect Dis. $1972 ; 126 \quad$ (2): $123 \quad-130$ doi:10.1093/infdis/126.2.123
75. Parker, J. C., Cross, S. S., and Rowe, W. P. Rat coronavirus (RCV): a prevalent naturally occurring pneumotropic virus of rats. Arch Gesamte Virusforsch. 1970; 31 (3): 293-302

76. Wojcinski, Z. W., and Percy, D. H. Sialodacryoadenitis virus-associated lesions in the lower respiratory tract of rats. Vet Pathol. 1986; 23 (3); 278-286

77. King, A., Adams, M. J., Carstens, E. B., and Lefkowitz, E. Virus Taxonomy 1st Edition, Ninth Report of the International Committee on Taxonomy of Viruses. London; Waltham: Academic Press, 2012.

78. Murray, J., Kiupel, M., and Maes, R. Ferret coronavirus-associated diseases. Vet Clin North Am Exot Anim Pract. 2020; 13 (3): 543-560.

doi: $10.1016 /$ j.cvex.2010.05.010

79. Have, P., Moving, V., Svansson, V., et al. Coronavirus infection in mink (Mustella vision): Serological evidence of infection with a coronavirus related to TGEV and porcine epidemic diarrhea virus. Vet Microbiol. 1992; 31(1): 1-10.

80. Milek, J., and Blicharz-Domanska, K. Coronaviruses in avian species-Review with focus on epidemiology and diagnosis in wild birds. J Vet Res. 2018; 62 (3): 249-255.doi:10.2478/vetres-2018-0035.81.

81. Peiris, J. S., Guan, Y., and ky, Y. Severe acute respiratory syndrome. Nature Medicine. 2005; 10: S88-597. doi:10.1038/nm1143.

82. Chan, J. F., Kok, K. H., Zhu, Z., Chu, H., To, K. K., Yuan, S, and Yuen, K. Y. Genomic characterization of the 2019 novel human-pathogenic coronavirus isolated from a patient with atypical pneumonia after visiting Wuhan. Emerg Microb Infect. 2020; 9 (1): 221-236 